\title{
The Identity of Cultural Arts: Thai Massage at Wat Pho to Communicate the English Materials for Tourism.
}

\author{
Kitda Praraththajariya
}

\begin{abstract}
The main study of this work was to communicate the identity of cultural arts: Thai massage at Wat Pho the to communicate English materials for tourism. There were two purposes the following items:

1) The identity of cultural arts: Thai massage at Wat Pho is located at Phra Nakhon district in Bangkok, Thailand. It is on Rattanakosin Island which is established directly south of the Palace. This temple is one of the six temples in Thailand as the highest level of the first-class royal temples. The temple was also the earliest center for public education in Thailand and originated a school of Thai medicine. It is known as the first traditional Thai massage.

2) The communication of the identity of cultural Arts: Thai massage at Wat Pho to communicate the English materials for tourism which the author found and designed to present in the English materials can be summed up Thai massage.
\end{abstract}

Index Terms - Thai massage, Wat Pho, tourism, Nuad Thai.

\section{INTRODUCTION}

Thai massage is approved of many countries and it makes Thailand that the Ministry of Tourism and Sports supports earnestly in the country. The Ministry of Tourism and Sports said foreigners have visited Thailand in 2015, 6.7 million persons come from ASEAN countries and the number is expected to grow to 8.3 million in 2016, generating 245 billion baht [1].Tourism has been one of the most interesting businesses to exist on the face of the globalization [2]. At the present, the tourism industries have been changed because they become interesting many more about experience packages [3]. They are divided into different sectors for example; transportations, accommodations, food and beverages, activities and etc. The local persons have moved to other places in their own areas. Thailand has met many problems for tourism but the Thai government could solve all problems well. The country was recently affected by natural disasters, internal and external events.

While the Tourism Authority of Thailand has advertised and supported the Thai identities that are valuable the historical sites, cultural arts and traditions in Thai way of life [4]. Some problems are occurred by misunderstanding from group of tourists who did not understand the imcome to Thai people. It is one of the types of tourism in

information such as the information of tourism sources, signs and Thai language. It occurs to misunderstand for communication. The information shows that the Thai identity is extremely necessary and important as each tourism resource. The way that the identity of the tourism resources is communicated is very essential to help foreigner tourists understand and learn these ideals. These groups are necessary to Thai tourism resources at Wat Pho or Wat Phra Chetuphon Vimolmangklararm Rajwaramahaviharn. In this research, Wat Pho is identified to tour: cultural art of Thai massage. The topic is useful for both the Thai tourists and foreign tourists. However, the important problems took place at Wat Pho that the communication to foreigners by using the English language is necessary. These various situations may reduce the number of foreign visitors at Wat Pho. Because Thai people at Wat Pho could not still communicate with the foreigner tourists by using the English language. This problem made the researcher must do this research for the tourist guides or tourist guide students. For this research, the researcher chose Wat Pho to be the research area because of many foreign tourists. They visited and massaged this place. Meanwhile, the research needed to help them understand Thai massage. Besides, ICOMOS (The International Council on Monuments and Sites) tried to communicate new events in the communities and the past civilization at the same time [5]. This function was important for the both the Thai people and the foreigner's younger generations to learn. If the researcher had not explored the topic for this research, it was possible the Thai massage at Wat Pho will not be understood this important tourism resource. The Thai massage at Wat Pho is a historic site which identify Thai culture, original tradition, ancient customs and Thai life styles. These will identify the identity of cultural arts: Thai massage at Wat Pho. This Thai massage at Wat Pho is an interesting historic site where is associated with the first King Rama who rebuilt this temple complete and became his main temple. It is impressed for Thai people. Furthermore, Wat Pho or Phra Chetuphon Vimolmangklararm Rajwaramahaviharn is the first university of the Thai medicine and massage where would be preserved and taught to future generations. Wat Pho is the national headquarters for the preservation and teaching of traditional Thai medicine and massage. It is opened from 8.00 a.m.to 18.00 p.m.

\section{OBJECTIVES OF THE RESEARCH}

work was supported in part by the research and development institute, Suan Sunandha Rajabhat University, Thailand.

Kitda Praraththajariya is with Humanities and Social Sciences, Suansunandha Rajabhat University 1 U-Thong Nok Dusit District, Bangkok10300, Thailand (e-mail: kitda@hotmail.com, kitda.pa@ssru.ac.th)
1) To study the data and analyze the identities of cultural arts: Thai massage for tourism.

2) 2. To communicate the identity of cultural arts: Thai 
massage at Wat Pho for tour developed the sustainable materials as a communication some tourism.

Methodology

The Identity of cultural arts: Thai massage at Wat Pho to communicate English materials for tourism. This research is qualitative research. The objectives of this research are the The Identity of cultural arts: Thai massage for tourism.

Population and Samples

There are three groups of samples that are outlined in the following items:

1) The key informant group at Wat Pho is five persons: the local persons and the massage practitioners at Wat Pho.

2) The foreigner group was made up of ten persons per day who visited Thailand. The researcher interviewed the ten people for the foreigner group by the following criterions:

- The foreigner group who had visited at Wat Pho, Thailand more than once.

- The foreigner group who specially visited at Wat Pho, Thailand, and did not go to any other places.

- In this case for the foreigner group, if a group included two persons traveling together only one person was chosen for the interview.

There are also the following conditions:

1) The age of the tourists interviewed is more than twenty years old.

2) There are ten foreigners tourists from Malaysia and Republic of the Union of Myanmar.

The five key informants had worked at Wat Pho for five years work experience. Their education graduated bachelor degree.

\section{DELIMITATION OF RESEARCH PROPOSAL}

\section{Delimitation of Research Proposal}

During this research, the researcher conducted the study at Wat Pho to study the data to analyze the identity and communication at Wat Pho for tourism. This study was conducted from June 2014 to May 2015.

\section{ANALYZING THE DATA AND WRITING THE RESEARCH REPORT}

The authors studied the documents and the data from the interviews and analyzed the content analysis. Then, all data were sumarized. Most of foreign tourists visited at Wat Pho, Bangkok came from Malaysian and Republic of the Union of Myanmar. They felt satisfied to visit at Wat Pho, Bangkok where one of royal temples nearby Main Street and the Grand Palace is. Moreover, they felt happy to massage the ancient Thai massage. Thai massage is legendary. It is related to Buddhism. In the past, most Thai people were concerned with temples (WATS) where many activities of the local communities took place. The temples became the best places to study not only Buddhism but also the traditional medicine. Thai massage was taken place at Wat Pho first so Wat Pho was the first traditional medical school. Today, Thai massage is well-known around the world. Many foreigners travel to Thailand and are interested in
Thai massage. Nowadays, there are many spas throughout Thailand where Thai massage is available [6].

Traditional massage started about 2,500 years ago. The ancient medical text was found in a stone inscription on the wall at Wat Pho in Bangkok. The father doctor who discovered the massage was Shivaga Komarpath, the Lord Buddha's doctor. Massage originally came to South East Asia from India. The people who exchanged ideas and techniques of massage came from different countries such as China, India, Burma and Tibet. Traditional Thai massage was also called Thai Yoga Therapy. At present, it is called Nuad Phaen Boran or Nuad Thai. It is a unique form of bodywork.

There is a unique style in each area of Thailand. Most Thai people are agriculturists. Their muscles become sore and tired due to the fact that they work hard all day long. Parents or adults teach massage skills to their children. The knowledge of how to massage is transferred from generation to generation. Traditional Thai massage includes proper nutrition, physical exercises, the use of medicine herbs and therapeutic massage. Traditional Thai medicine is not only concerned with curing diseases and ailments but also is maintaining health and well-being. Ancient Thai people believed that not to be ill is the best blessing. The medical knowledge was developed by Thai people through many generations [6]. It became a part of the ancient wisdom of Thailand.

The knowledge that was inscribed on the walls at Wat Pho in Bangkok illustrates one of the fundamental principles of traditional Thai medicine that is energy flows through the body along major tendons that are called Sen En. The inner body has energy flow approximately 72,000 energy lines. When this energy flow is blocked or restricted, sickness or diseases may develop. When the energy in the body is obstructed to flow through these channels, the body feels pain. Traditional Thai medicine is similar to various other ancient healing systems in which illnesses are caused by an imbalance or obstruction within each person or by an imbalance between each person and environments. Wat Pho Thai Traditional Massage School is the center of massage services and study in Thailand.

Ancient Thai people treated a number of ailments by using massage to restore the flow of energy throughout the body. Traditional Thai massage is a full body treatment which includes both stretching of the joints and muscles and applied pressure to the tenders. Thai massage is a very wide spread treatment in Thailand. Thai massage pressed each point to move slowly. The muscle is pressed which is stretched in the body. Thai medical massage can move deeper into the mechanical functions of the body, working with deep muscle tension and joint movements as well as nerve, muscle and ligament balancing. In the health care system this treatment is an efficient method. Moreover, it is a very successful treatment.

The purpose of Thai massage is to bring the body, mind, and spirit into the balance and harmony and it provides an opportunity for self-healing. This massage is one of the most beneficial therapies for treating physical and psychological problems, maintaining health and well-being. There are six main points of Nuad Boran or Traditional Thai massage. They are yoga, exercises, mediation, reflexology, 
acupressure and healing art. The benefits of traditional Thai massage are relaxation, oxygen flow, ability to absorb nutrients, reducing muscle tension, back and shoulders aches, headaches, neck aches, improve nervous system, reducing stress, strength and rejuvenation of the body, circulation of blood, flexibility, balancing of energy flow, balancing of body, mind and spirit. It also reduces pain relief, anxiety, depression, blood pressure and heart rate. Thai massage can be particularly helpful in relieving: headaches, migraines, arthritis, whiplash pain, paralysis, numbness, sciatica, back pain and other conditions. Other benefits of traditional Thai massage include blocking pain signals to the brain, and improving sleep but these benefits have not been supported by extensive clinical studies. Thai Massage combines the application of pressure which is used by hands, thumbs, elbows, forearms, feet and knees. Not only the muscles are adjusted to stretch but also the health is balanced to well-being. Then, the energy pathways are cleared. The muscles are stretched. The joints are circulated. The internal organs and all bodily functions are supported to move towards a balanced body.

As a whole, massaging is used by hands, elbows and feet and presses on the body. Each massage takes different time. Some types of massage last from one to two hours. The equipment is mat or mattress which is lain down on the ground. The patients must change their clothes. Their clothes are pajamas. The massagers follow step by step of massage. The techniques of massaging are gentle pressure on the patients' body. While the massagers pull fingers, toes and step on the patient's back. They use oil and massage all of the patients' body. Some patients feel hurt some time. Finally, the patients feel comfortableness.

The qualities of massage are necessary to patients for healing. There are various steps of massaging. The practitioner usually uses thumbs to press on each muscle of the body to untwist. The pressing helps blood to flow into each blood vessel. Moreover, the practitioner decreases to press these points and the blood flows into those points. It makes the blood system circulate efficiently. Although the practitioner uses the pressing efficiently, rolling is a therapy. The practitioner uses thumb, fingers and back to help by using strong press to the muscle. The practitioner catches a lot of muscle with full hands by using strong expression. This method circulates the blood vessels into the muscle. It makes the patient relax and also easier to stretch. The practitioner uses tugging to exercise to seize the muscle or fascia of the articulation, which is shrunk, becomes extended. Then, the practitioner twists the muscle to extend in the right way. The muscle is bent to move to the articulation. It is necessary to press quite hard. For slapping or pounding, if the patient has backache, the slapping is stimulated in rhythm at the back. It helps to get rid of phlegm if the patient has a cough and sneeze. Some patients need to be walked and stepped on their backs. This massage is popular with Thai people. It is very good for relaxation. The organs for massaging are fingers, palms, backbone and hands. The middle fingers are used to touch with the thumbs to press for massaging. The fingertip is not used to put on the points but all fingers are placed on the points. Palms are placed and pressed on the muscle. The muscle cannot be pressed by fingers. If the muscle is biceps, the muscle is pressed deeply by backbone. It is slapped to stimulate the muscle in rhythm. The twisting of the muscle to extend is done by two hands. On the other, it is bent to connect the joints and cannot move normally. Not only hands but also elbows are used to press or roll on the points where the fingers cannot press quite deep such as shoulder muscle and the sole of the feet. Moreover, feet are stepped on the thick spots but the feet must not step on the patient's back because the spinal bone might break or harm the inside organs.

Thai foot massage was developed over the years by incorporating foot massage techniques from some places such as China, Japan, and Korea. The foot is probably the lowest part of the body which is related to a direct connection to every other part of the body. Good Thai foot massages not only make feet feel the relaxation but also can promote healing and relaxation in many other parts of the body as well. The basic reflexology is certain points on the feet that can affect other areas of the body. Reflexology comes from the words reflex and logy. Reflex means a reflection and logy means study. When reflex is mixed with logy, this word is reflexology. Reflexology is a treatment which involves pressing with hands and massaging on feet. Both of them are related to every organ, gland, and various systems of the body. This process of reflexology decreases tension. It brings energy, balance, and creates the feeling of relaxation and well-being as a full body massage. The soles are a second important part. Because of the blood, it flows from the heart through the whole body and it flows to the feet. The blood flows back to the heart again. The feet are like the second important heart in the human being. The soles have various important points which can explain the conditions in the body from the reflection to the soles. The practitioners are able to analyze each sole carefully.

Foot reflexology is pressure therapy and it involves focused pressure to certain known reflex points which are located in the feet to cure or prevent diseases. Foot reflexology is based on the mapping which shows nerve zones or reflex points from soles to the top of a head. The head is an important organ of the body. A practitioner can put press on different energy lines on the soles and the side of the feet to determine the cause of illness. Moreover, pressure is applied to the feet and hands using specific thumbs, fingers and hand techniques. Stretch and movement techniques are utilized to provide relaxation to the foot. Oil, cream and lotion are not utilized in traditional reflexology work.

At present, the traditional Thai massage is a holistic massage therapy which focuses on the whole body. Thai massage is also called Thai yoga massage because the practitioner uses his or her hands, knees, legs, and feet to move the patient into steps of yoga as stretches. Many people say Thai massage is similar to doing yoga without any work. Muscle compression, joint mobilization, and acupressure are also used during treatment. Its purpose is to cure the ailments of all various elements into the balance of the body. This massage removes the obstructions from the tendons. The soft physical pressure relieves muscular tension, removes stress from the body and the mind of the patients and increases the flexibility of the muscles and limbs. It also helps in imbalances in the nervous system. Traditional Thai massage improves blood and lymph 
circulation. This therapy ensures patients can relax and it refreshes the spirit.

\section{DISCUSSION AND CONCLUSION}

This report analyzed "The identity of cultural arts: Thai massage at Wat Pho for tourism by the following item: Thai massage.

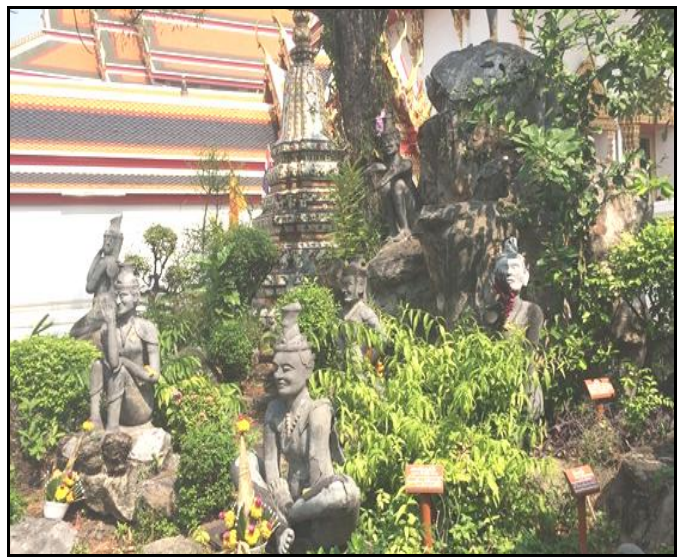

Fig. 1. Hermit statues in Wat Pho.

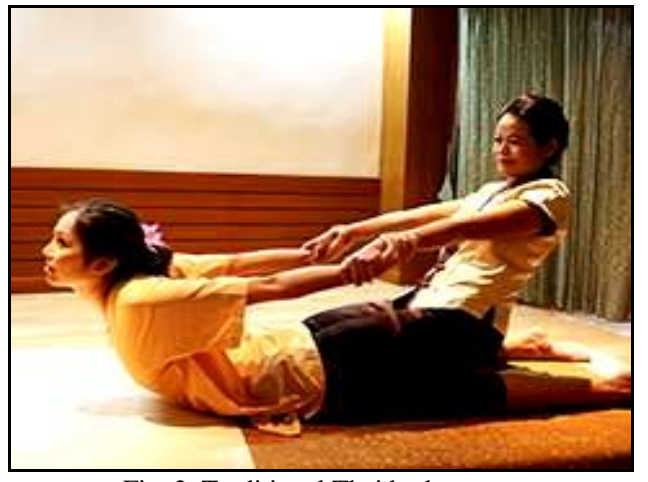

Fig. 2. Traditional Thai body massage.

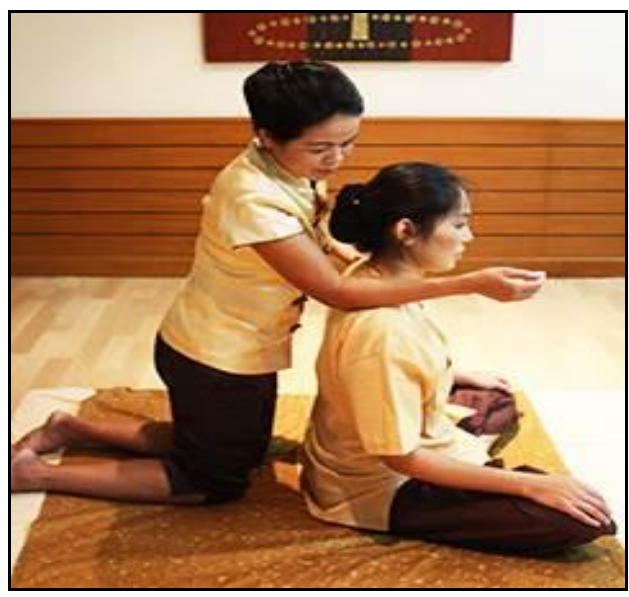

Fig. 3. Thai back massage, head massage and shoulder massage. ararm Rajwaramahaviharn area.

Tourism has grown massively as an industry over the past century for a variety of reasons [7]. For example, advances in travel are a wider range of ways to travel as a tourist and these methods are widely available technology. Tourism growth can be limited on a local scale [8]. Culture which is primarily transmitted to individuals through groups and across generations. It is believe that actions are learned through interactions with others [9]. The interactions happen to human in many activities to communicate each other. It is art of perception to understand the contents. Wat Pho is an important temple in Thailand and well known about traditional Thai massage. The traditional Thai massage is a cultural art which is popular for curing the body. If the patients do not see the doctors. This method is one alternative of types of curing of body. Many Thai people are interested in the massage. They go to Wat Pho for visiting and massaging. Every weekend the traditional Thai massage school are full both patients and massagers. The visitors can see clearly this school. They get smell Thai herbal oil or herbal balm and the patients inside the building. Both Thai and foreigner people visit here for visiting around temple and learning how to massage the traditional Thai massage. The Thai massage is an identity of Thai cultural art in Thailand since the ancient period. The traditional Thai massage has many types such as body massage, back massage, head massage, shoulders massage and etc. Traditional Thai body massage is a combination of deep tissue, pressure points and stretching techniques to reduce stress and relieve muscle soreness. For Thai back massage, head massage and shoulders massage are wonderful massages which were used herbal balm to help release stress and tension, refreshing and restoring a sense of serenity. Then, Thai foot massage is a relaxing therapy involving gentle foot massage using a special balm, followed by a pressure point massage to improve blood circulation and revive your tired legs and feet. The Thai massage at Wat Pho is an individual experience if you visit Wat Pho. It is still a unique experience. Besides, the prices for massage treatments at Wat Pho are the following items: Traditional Thai massage 420 baht for 1 hour 260 baht for 30 minutes.

Studying the identities of cultural arts: Thai massage at Wat Pho in the English language made foreign tourists understand the identity of cultural arts: Thai massage in Thailand better for visiting at Wat Pho, Bangkok.

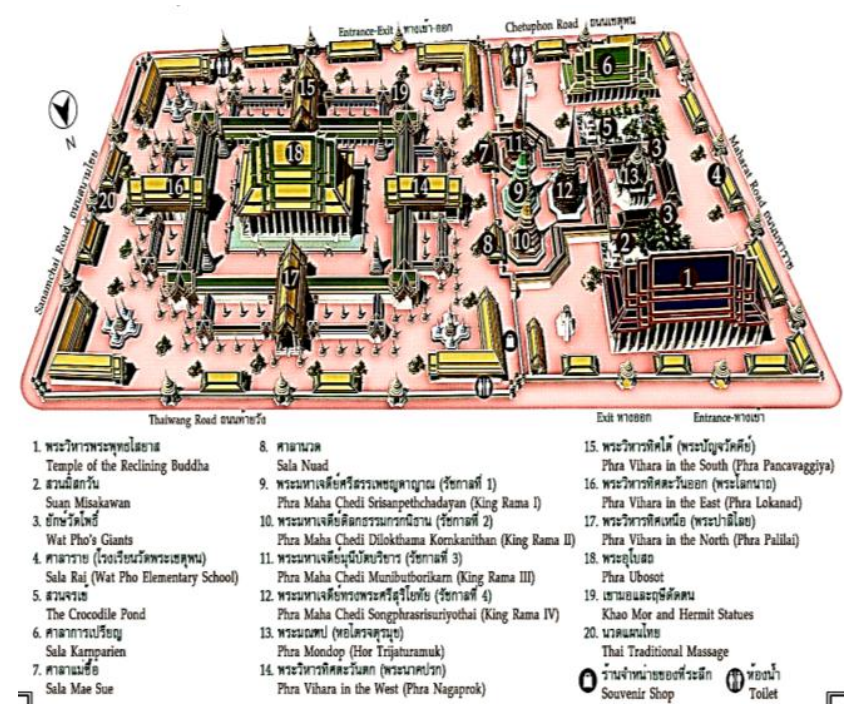

Fig. 4. Wat Pho or Phra Chetuphon Vimolmangkl.

\section{A. Suggestion for the Next Research}

This research is the Identity of Cultural Art: Thai massage at Wat Pho to communicate in the English language for tourism. Besides, it can be applied to the next research for 
other temples or historical sites. This research about Thai massage is an good interesting activity for the foreign tourists. And it can be also changed to be the identity of other temples for cultural tourism, sustainable tourism, etc. in the future that would be a good research to study.

\section{ACKNOWLEDGMENT}

This research is "The Identity of Cultural Arts: Thai massage at Wat Pho to communicate in the English language for tourism"

This research would not have been successful without the guidance and support from individuals who were valuable assistance in the preparation and completion of this study.

This research was support by Suan Sunandha Rajabhat Research and development institute.

Furthermore, the researcher would like to say thank you once more from sincerely heart to acknowledge the key informants, the foreigner tourists and the tourist guides. They are very important persons who made me successful my research.

\section{REFERENCES}

[1] Tourisms and sport ministry. (2015). [Online]. Available: http:// www.mots.go.th/main.php?filename =index_EN

[2] S. Chetanont, Chinese Tourists's Behaviors Towards Travel and Shopping in Bangkok, 2014.

[3] E. S. David and C. K. Sung, Managing Ecotourism: A Legacy for the Future, New York.: Haworth Press, 2015.

[4] K. Praraththajariya, "Thai way of life," Bangkok.: Kasembandit, 2010.

[5] ICOMOS Charter for the interpretation and presentation of cultural heritage sites. [Online]. Available: http://www.icomos.org.

[6] The Impact of Culture on Tourism. (2015). [Online]. http: www. oecd.org/cfe/tourism theimpactofcultureontourism.htm

[7] M. Intosh, W. Robert, C. R. Goeldner, and. J. R. Ritchie, Tourism: Principles, Practice and Philosophies $\left(7^{\text {th }}\right.$ ed.), New York.: John Wiley \& Sons, 2015.

[8] T. Somying, "Travel and tourism entrepreneurs," Chonburi.: Wattanasi, 2010

[9] Communication theory. (2015). [Online]. Available: http://www.researchomatic.com/communication-theory 182748

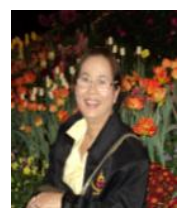

Kitda Praraththajariya was born in 1956 in Bangkok, Thailand. She obtained a master degree in English.

She is a lecturer in field of English language with the Faculty of Humanity and Social Science, Suan Sunandha Rajabhat University, Bangkok, Thailand. 